\title{
O cooperativismo como instrumento para a autonomia de comunidades rurais da Amazônia: a experiência dos agricultores extrativistas do município de Lábrea, AM
}

(Cooperativism as an instrument for the autonomy of rural communities in the Amazon: the experience of extractive farmers in the municipality of Lábrea, AM)

Lindomar de Jesus de Sousa Silva' ${ }^{1}$, José Olenilson Costa Pinheiro², Endrio Morais dos Santos ${ }^{3}$ Embrapa Amazônia Ocidental, Manaus (Brasil)

Jemima Ismael da Costa 4 Universidade Federal do Amazonas (Brasil)

Gilmar Antonio Meneghetti ${ }^{5}$ Embrapa Clima Temperado - Pelotas (Brasil)

Sumário: 1.Introduçao. 2.Referencial Teórico. 3. Medologia de Pesquisa. 4. Resultado. 4.1. A origem e a importância da organização da cooperativa. 4.2. Impactos econômicos da cooperativa na comercialização dos produtos extrativistas. 5. Considerações finais. 6 . Referencias bibliográfica

Summary: 1.Introduction. 2. Theorical framework. 3. Research Methodology. 4. Result. 4.1. The origin and importance of the organization of the cooperative. 4.2. Economic impacts of the cooperative in the marketing of extractive products. 5. Final considerations. 6. References.

1 Sociólogo, Doutor, pesquisador da Embrapa Amazônia Ocidental-Manaus, AM. E-mail: lindomar.j.silva@embrapa.br

2 Economista, Mestre, pesquisador da Embrapa Amazônia Ocidental, Manaus (AM). E-mail: jose.pinheiro@embrapa.br

3 Bolsista de Iniciação Científica, Paic/Fapeam/Embrapa Amazônia Ocidental, Manaus, AM. E-mail: endrio.morais9@gmail.com

${ }_{4}$ Gestora Ambiental, Mestre em Ciências Ambientais - Universidade Federal do Amazonas. E-mail: jemima.ambiental@gmail.com

5 Agrônomo, Mestre em Desenvolvimento Agricultura e Sociedade, pesquisador da Embrapa Clima Temperado - Pelotas, RS. E-mail: gilmar.meneghetti@embrapa.br 
Resumo: O presente artigo trata da organização das comunidades extrativistas do município de Lábrea, no Amazonas, Brasil, e de como a cooperativa foi essencial para a superação dos desafios socioeconômicos em que vivem os extrativistas da Amazônia. A coleta das informações foi realizada através de visitas e entrevistas com extrativistas, lideranças das comunidades e organizações que atuam na região. Como resultados, concluímos que a criação da Cooperativa Mista Agroextrativista Sardinha (COOPMAS), com a mediação de instituições, possibilitou a organização da produção extrativa e agrícola, a superação do atravessador e comercialização justo para os produtos extrativista e agrícola, além de ter facilitado o acesso a políticas públicas, como crédito, assistência técnica e mercados, contribuindo para a emancipação socioeconômica e política dos extrativistas.

Palavras-chave: extrativistas, organização social, cooperativa, renda, autonomia.

Abstract: This article deals with the organization of extractive communities in the municipality of Lábrea, in Amazonas, Brazil, and how the cooperative was essential for overcoming the socioeconomic challenges faced by extractivists in the Amazon. The collection of the information was made through visits and interviews with extractivists, leaders of the communities and organizations that operate in the region. As a result, we conclude that the creation of the Cooperativa Agroextractivista Sardinha (COOPMAS), with the mediation of institutions, made possible the organization of extractive and agricultural production, overcoming the travester and fair trade for extractivist and agricultural products, as well as facilitating access to public policies such as credit, technical assistance and markets, contributing to the socio-economic and political emancipation of extractivists.

Keywords: extractivists, social organization, cooperative, income, autonomy. 


\section{Introdução}

O comércio de produtos extrativistas encontrou na Amazônia grande quantidade de itens ${ }^{6}$ capazes de encher os "olhos de muita gente», principalmente de comerciantes (BATISTA 2007, 33). Entre esses produtos está a castanha-do-brasil. A valorização dos produtos extrativos no mercado europeu fez com que, em pouco tempo, a região amazônica fosse ocupada por comerciantes e aventureiros ansiosos por lucros rápidos e fáceis.

Como consequências da pujança do comércio extrativista, intensificou-se a exploração dos povos indígenas ${ }^{7}$, seguida da população de negros $^{8}$ e nordestinos 9 , de diferentes formas, escrava, social e econômica, para garantir os interesses da elite comercial da Amazônia, sob demasiada exploração humana em plena selva. Para BENCHIMOL (2009), esse modelo produz na Amazônia um grande contraste: o de ser uma região rica, com uma população que há tempos amarga a pobreza e a exclusão secular, situação permanentemente renovada por um círculo de carência e miséria.

A consequência do processo de exploração extrativa conduzido por colonos, comerciantes e aventureiros forjou uma estrutura usurpadora

6 O estoque de espécies nativas presente na Amazônia, conhecidas como drogas do sertão, promoveu uma grande corrida ao interior da floresta para a extração de produtos como resinas, frutos, cascas, bulbos e folhas. Esses produtos, uma vez coletados, eram vendidos no mercado europeu. Entres os principais produtos comercializados estavam: o anil, o cacau, a salsaparrilha, o óleo de copaíba, favas de baunilha, o pau-cravo, a castanha-do-brasil e a borracha.

7 Segundo CARDOSO $(1984,98)$, a perseguição e escravidão indígena eram justificadas pela incapacidade financeira dos comerciantes em adquirir escravos negros. Para o autor, "a impressão de pobreza, marasmo e abandono, numa colônia, onde a atividade principal - a extração silvestre de "drogas do sertão» como o cacau, a salsaparrilha, a baunilha, o pau-cravo, etc.- era puramente predatória». CARDOSO (1984, 98) diz que «só em 1748 decidiu a metrópole introduzir no Pará a economia monetária, efetivando-se tal medida em 1752, quando o Estado português providenciou o envio de dois mil réis; antes corriam como moeda o cacau, o cravo, a salsaparrilha, o açúcar, novelos de algodão, etc».

8 A escravidão negra para atividades extrativistas na Amazônia foi resultado do apelo das autoridades e de colonos, devido ao impedimento e à resistência da utilização dos indígenas na coleta promovidos pela Igreja e pela legislação governamental (SAMPAIO, 2011).

9 Segundo SOUZA (1978), entre 1890 a 1910, a quantidade de nordestinos que migrou para a Amazônia foi superior a meio milhão, expulsos pela grande seca de 18771880. NASCIMENTO $(1998,3)$ afirma que esses migrantes passaram a trabalhar na produção da borracha, elevando-a para « $40 \%$ do total da exportação brasileira já em 1910». 
da natureza e das comunidades amazônicas, sejam os povos autóctones ou transplantados (negros e nordestinos). Criou-se na maior floresta tropical do planeta o que $\operatorname{SEN}(2010,9)$ chama de um «mundo de privação, destituição e opressão extraordinária», onde "a persistência da pobreza», a fome coletiva e crônica convivem rotineiramente com a «violação da liberdade», como também a constante ameaça ao «meio ambiente e à sustentabilidade» econômica e social.

Entre as regiões amazônicas que vivenciaram o sistema extrativo de exploração dos recursos florestais, vegetais e animais (peixe-boi, tartaruga e pirarucu, principalmente) ${ }^{10}$, com ampla consequência ao meio ambiente e à vida humana, estão as banhadas pelos rios Purus, Ituxi e seus afluentes, no estado do Amazonas, Brasil. Essas regiões têm suas histórias narradas por viajantes e cronistas desde anos de 153911. Porém é no século XIX, com a descoberta da borracha natural, extraída a partir do látex da seringueira (Hevea brasiliensis), que a região passou a ter a presença efetiva de colonos, comerciantes e aventureiros e das companhias de navegação que vieram em busca da grande riqueza natural e a possiblidade de lucro no mercado mundial. A exploração da borracha criou, em 1873, a cidade de Lábrea, fundada pelo coronel Antônio Rodrigues Pereira Labre, dono de seringais e um dos poucos a enriquecer com a exploração dos recursos naturais da Amazônia, principalmente a borracha.

$\mathrm{Na}$ floresta desconhecida e inóspita, muitos sucumbiram, e os que sobreviveram passaram a viver sob o jugo do aviamento, uma forma de crédito que, como diz ARAMBURU $(1994,1)$, «une o mundo do caboclo, por mais isolado que esteja, à sociedade regional e nacional, e em última instância ao mercado mundial». Para o autor, o paradoxo desse instrumental de crédito estava no fato de «introduzir o caboclo na divisão internacional do trabalho, na 'modernidade' do mercado mundial e, ao mesmo tempo, a principal barreira ao desenvolvimento e à modernização da vida e das relações sociais na Amazônia».

Com o passar do tempo, a borracha caiu em decadência, perdeu a importância, e as famílias continuaram sendo aviadas, agora para a coleta da castanha-do-pará e outros produtos florestais e alguns agrícolas com valor econômico. Isoladas e sem acesso à informação, amargaram

10 Link (2017) apresenta um relato da exploração florestal, vegetal e animal na região do Purus.

11 O dominicano Gaspar de Carvajal, integrante da expedição comandada por Orellano, em 1539, relata sua visão sobre o Rio Purus: «No Domingo da Ascensão viram na direita um rio poderoso, cuja entrada era tão grande que formava três ilhas... Havia muitas e grandes populações, e a terra era linda e frutífera». 
condições subumanas no meio da selva, forçadas a submeterem-se a tais condições ou a migrarem para as cidades. Situação que somente pode ser revertida com acesso a políticas públicas, participação social e à tecnologia.

A importância organizativa da cooperativa para a superação dos limites socioeconômicos que fortalecem a vulnerabilidade dos extrativistas e o jugo aos patrões e comerciantes é analisada neste artigo a partir do estudo da Cooperativa Mista Agroextrativista do Sardinha (COOPMAS), instrumento econômico que permitiu aos extrativistas caminharem em direção ao bem-estar, com maior valorização do trabalho de coleta da castanha e maior retorno financeiro e consequentemente desenvolvimento familiar e comunitário.

A cooperativa estudada é uma organização coletiva gerenciada de forma autônoma pelos extrativistas. Tal condição organizativa ainda é pouco comum em muitas regiões da Amazônia. Porém o estágio de organização é consequência de fatores sociais, econômicos e políticos.

O município de Lábrea está localizado em uma região de grande interesse para expansão da pecuária e da fronteira agrícola do País. Essa condição fez do município um local de tensões e conflitos entre extrativistas e pecuaristas a partir da década de 1970. Nesse contexto, os extrativistas reagiram com o fortalecimento do seu sistema organizativo, principalmente por meio da participação nas Comunidades Eclesiais de Base (CEBs) e com a articulação com as entidades mediadoras, como a Comissão Pastoral da Terra (CPT), o Conselho Nacional dos Seringueiros (CNS) e mais recentemente o Instituto Internacional de Educação do Brasil (IEB), que, por meio de encontros comunitários e atividades de formação e assessoria permanentes, despertou nos extrativistas a necessidade de uma ação reativa ao domínio dos atravessadores, comerciantes, fazendeiros e outros segmentos capitalizados da região, no que diz respeito ao comércio dos produtos do extrativismo, à apropriação da terra e à degradação do ambiente. Nesse contexto de reação ganhou força entre os extrativistas a ideia e necessidade de criar uma associação comunitária e cooperativa como instrumentos para fortalecer a ação coletiva em seu viés social e econômico.

O processo histórico formativo e organizativo vivenciado pelas comunidades do Purus possibilitou a consolidação de grande número de associações comunitárias, como a Associação dos Produtores Agroextrativistas da Colônia do Sardinha (ASPACS). A associação foi fundada em 1997 por um grupo de agricultores e extrativistas com a «finalidade de apoiar a comercialização dos produtos não-madeireiros (castanha, óleo de andiroba e borracha) e minimizar as dificuldades de escoamento da produção, tanto dos produtos não madeireiros como os cultivos ali- 
mentares» (NODA 2008, 53), e com o crescimento e fortalecimento da produção e das comunidades foi fundada depois a Cooperativa Mista Agroextrativista do Sardinha (COOPMAS), em 2009. A cooperativa assumiu o papel de viabilizar economicamente os extrativistas e passou a comercializar a produção de castanha-do-brasil, borracha e de outros produtos extrativos não madeireiros e agrícolas, como também passou a ser a organização responsável por gerenciar a usina de beneficiamento de castanha de Lábrea, implantada com recursos do Banco Nacional de Desenvolvimento Econômico e Social (BNDES).

A associação e a cooperativa, criadas e gerenciadas pelas extrativistas com apoio do órgão de assistência técnica e organizações sociais, tornaram-se importantes instrumentos econômicos, políticos e sociais capazes de dinamizar a produção extrativista e agrícola no município, além de passarem a figurar como exemplo a muitas comunidades e instituições de todo o estado do Amazonas.

Uma das maiores conquistas da cooperativa foi a criação das condições necessárias para que os extrativistas deixassem de vender para os atravessadores e comerciantes. A cooperativa foi, portanto, uma estrutura ideal para superação do «oligopsônio/oligopólio» que predominava há décadas no mercado dos produtos extrativistas e agrícolas do município (HOMMA, MENEZES 2014, 205).

O presente artigo é resultado de um conjunto de levantamentos, visitas e entrevistas com extrativistas e lideranças das comunidades, associação e cooperativa, como também de instituições e organizações que atuam na região. Tais informações foram sistematizadas e estão apresentadas neste texto.

No Amazonas, os extrativistas e agricultores enfrentam grande dificuldade para se organizarem, o que facilita a exploração dos atravessadores e comerciantes. Diante desse contexto, relatar a experiência organizativa das comunidades do município de Lábrea é importante, porque mostra o potencial da organização coletiva para o desenvolvimento das comunidades rurais, além de criar condições para que elas superem a situação de dominação econômica e social presente há décadas no interior da floresta. Com a cooperativa, os preços melhoraram, os extrativistas ampliaram sua produção e passaram a ter acesso a créditos e novos mercados, além de outros benefícios.

\section{Referencial teórico}

Uma das grandes preocupações da humanidade com a Amazônia é a sua manutenção. Para isso há muitas organizações que se voltam 
para o fortalecimento de atividades produtivas sustentáveis realizadas por extrativistas e agricultores no interior da floresta.

No rol das atividades produtivas com potencial de ser sustentável está o extrativismo vegetal e animal. Para SIMONI $(2010,49)$, o extrativismo é capaz de conservar e manter a floresta, com geração de renda para as comunidades, o que faz dele «uma atividade produtiva modelo em ações de desenvolvimento sustentável, pois concilia interesses de conservação e necessidades de desenvolvimento socioeconômico».

Para SILVA $(2015,241)$, a solução para manutenção e conservação da Floresta Amazônica está em "produzir com respeito ao meio ambiente, caminho mais seguro, o único na verdade, capaz de possibilitar a implantação de uma agropecuária sustentável». Para o autor, «desenvolver o estado e a região é garantir a defesa de nosso ecossistema, significa banir o predador e preservar nossa biodiversidade». Para isso é necessária a ação do Estado, pois «a destruição se alastra exatamente no vácuo gerado pela ausência de políticas públicas», em que o bioma «está desguarnecido, entregue à própria sorte» .

No debate que envolve o fortalecimento de alternativas que possibilitem o desenvolvimento sustentável da Floresta Amazônica é preciso considerar fatores tecnológicos, que podem aperfeiçoar o sistema de produção e coleta de produtos extrativistas; econômicos, principalmente relacionados à comercialização e ampliação dos mercados; e organizativos e políticos, de forma que os extrativistas sejam partícipes de uma "sociedade cada vez mais reflexiva», marcada "por elevados níveis de auto-organização» (GIDDENS 2001, 91).

O fortalecimento das comunidades extrativistas essencialmente precisa ser numa perspectiva associativa e cooperativa, já que é «a capacidade de comunicação e de colaboração que se funda uma parte essencial da qualidade de seus resultados» (LONDERO 2009, 53).

Todos os processos relacionados a ganhos econômicos, sociais, políticos e ambientais das comunidades amazônicas, que vislumbram projetos e ações de desenvolvimento sustentável, são decorrentes de processo organizativo. Como diz HECK, LOEBENS e CARVALHO (2005, 238), as comunidades amazônicas precisam estar organizadas para a sua «sobrevivência e para a sobrevivência da região. Há, hoje, uma luta articulada na Amazônia, constituída em grandes redes de resistência, conhecimento, reflexão e alianças». A organização das comunidades fez com que "a questão ambiental não pudesse mais ser tratada como uma questão sem sujeito» e restrita a "um quadro natural isolado, pensado preponderantemente por botânicos e biólogos» (ALMEIDA 2008, 21). Para ALMEIDA (2008, 21), as comunidades amazônicas superaram a "existência individual ou atomizada», passando à 
construção de sujeitos coletivos que se « vinculam ao advento dos vários movimentos sociais que passaram a expressar as formas peculiares de uso e de manejo dos recursos naturais por povos indígenas, quilombolas, ribeirinhos, seringueiros, quebradeiras de coco de babaçu, ou seja, pelas denominadas populações tradicionais».

Na maioria das análises relacionadas à organização das comunidades amazônicas, destacam-se o Conselho Nacional dos Seringueiros (CNS), os Movimentos dos Atingidos por Barragens (MAB), os Movimentos dos Pescadores Artesanais (Movimento Nacional dos Pescadores, Monape) e muitos outros que conseguiram ser importantes instrumentos de incidência junto aos poderes públicos municipal, estadual e federal. Porém há diversas organizações comunitárias e territoriais que atuam nas gestões de lagos e no desenvolvimento da produção extrativista, agrícola e animal. Como diz LIRA e CHAVES (2016, 72), são organizações políticas «marcadas e orientadas por uma identidade pautada nos valores socioculturais e na dinâmica sócio-histórica da região amazônica».

A organização das comunidades extrativistas de Lábrea, como em outros territórios amazônicos, constitui um processo de amadurecimento, de fortalecimento dos aspectos socioeconômicos, culturais e políticos das comunidades, como também uma ação de contraposição ao avanço de outras estratégias econômicas, pautadas pela degradação florestal e homogeneização da paisagem. E uma organização que se fortalece numa conjuntura difícil.

No caso das comunidades de Lábrea, a cooperação voluntária está associada a bom estoque de capital social decorrente do enfrentamento aos pecuaristas e madeireiros, que fortaleceu a confiança entre os extrativistas; a eficiência das organizações, com o desenvolvimento de ações articuladas e coordenadas. A luta das comunidades pela manutenção do seu modo de vida fortaleceu a união e a confiança entre os extrativistas. Essa confiança entre eles agrega mais às comunidades, colocando nas mesmas condições daquelas que são capazes de «realizar muito mais do que outro grupo que careça de confiabilidade e confiança» (Coleman 1990, 302).

No aspecto organizativo, observa-se a confiança fortalecida nas comunidades extrativistas na perspectiva da teoria do capital social formulada por PUTNAM (2006) e BOURDIEU (1998). PUTNAM (2006, 177) compreende a confiança em conjunto com normas e sistemas, que compõem uma organização social e contribuem diretamente para "aumentar a eficiência da sociedade, facilitando as ações coordenadas». ALBAGI e MACIEL $(2002,7)$ compreendem que a confiança funciona como um lubrificante da vida social e «sociedades com elevados 
graus de confiança tornam-se e permanecem ricas porque são cívicas. A confiança é por sua vez alcançada quando há um conhecimento mútuo entre os membros de uma comunidade e uma forte tradição de ação comunitária».

A reflexão relacionada ao capital social permite vincular a confiança "como resultante de uma coesão social ou redes sociais informais com objetivos comuns, pautadas em normas com alguns atributos como cooperação mútua, confiança, solidariedade, reciprocidade e tolerância» (RIBEIRO, ARAÚJO 2018,751). Para PUTNAM (2006, 180), quanto «mais elevado for o nível de confiança numa comunidade, maior a probabilidade de haver cooperação. E a própria cooperação gera confiança». O autor ressalta que a "confiança necessária para fomentar a cooperação não é uma confiança cega». Essa dinâmica de fortalecimento da coesão no grupo faz com que o capital social «aumente os benefícios de investimento em capital físico e capital humano» (PUTNAM 1993, 1).

No estudo construído por Putnam, o capital social é consequência de uma construção histórica, um tipo de herança que é alimentado pela experiência coletiva, é um tipo de capital que se multiplica com o uso, ou seja, a cooperação produz cooperação e confiança fortalece confiança, em um processo contínuo no grupo, e quanto maior for o sistema participativo, mais o indivíduo irá participar e cooperar visando aos benefícios mútuos. Nas «comunidades onde as pessoas acreditam que a confiança será retribuída, existe maior possibilidade de haver intercâmbio» (FERREIRA; PESSÔA 2012, 7).

O capital social, segundo RIBEIRO e ARAÚJO $(2018,751)$, tende a produzir externalidades positivas, com o aumento da «disponibilidade de informações, reduzindo as incertezas e os custos de transação, minimizando o oportunismo e podendo até facilitar o fornecimento de bens públicos, propiciando assim ganhos econômicos e de bem-estar para os agentes envolvidos».

ABRAMOVAY $(2000,384)$ diz que a noção de capital social mostra que os indivíduos não atuam sozinhos. É preciso pensar a estrutura social como um ativo, um capital, em que os indivíduos passam a vivenciar um «processo de aquisição de poder (empowerment, na terminologia que vem se consagrando entre as organizações internacionais de desenvolvimento) e até de mudança na correlação de forças no plano local».

Para BOURDIEU $(1998,67)$, o capital social é um «conjunto de recursos atuais e potenciais que estão associados à posse de uma rede durável de relações mais ou menos institucionalizadas de interconhecimentos ou, em outros termos, à vinculação a um grupo», que pos- 
sui propriedade comum e estão unidos por relações «permanentes e úteis». Na perspectiva de BOURDIEU $(1998,67)$, o capital social é «um agregado de recursos reais ou potenciais que estão vinculados a um grupo, por sua vez constituídos por um conjunto de agentes unidos por relações permanentes e de reconhecimento mútuo».

A compreensão de Bourdieu de capital social indica a presença de elementos relacionados ao saber, aos aspectos constitutivos; indica os benefícios oriundos da participação dos indivíduos em grupos sociais e a maneira como o capital social se reproduz. O capital social é construído e alimentado pelo crescimento das relações, que na medida em que se ampliam favorecem os indivíduos a acessarem os recursos em quantidade e qualidade. Para ROUTLEDGE e AMSBERG (1996, 2), o «capital social é criado quando relações são formadas».

Em Bourdieu, a ideia de quantidade e qualidade de recursos está relacionada à extensão de rede de relações mobilizada e à existência de diferentes formas de capital (econômico, cultural ou simbólico).

ORTEGA e MATOS afirmam que o capital social engloba um conjunto de pressupostos, que podem ser sistematizados em:

a) um conjunto de recursos resultantes da posse ou pertencimento a um grupo ou «corpo» social; b) nesse locus se desenvolvem «relações» com certo nível de institucionalização (logo, envolvendo, em algum grau, certas normas, valores e regras), que imprimem regularidades comportamentais ou cognitivas ao grupo ou «corpo» social, mas que também podem gerar conflitos que pressionam pela sua mudança, explicam seu caráter histórico (logo, evolutivo e temporal) e justificam sua dinâmica relacional; c) essas relações geram interconhecimento e inter-reconhecimento, que reforçam as regularidades comportamentais, tornando-as mais constantes, repetitivas e intensas, logo mais duráveis e permanentes; d) esse interconhecimento e inter-reconhecimento continuamente reforçado cria o «amalgamento grupal» de níveis diferenciados, ou seja, imprime propriedades comuns a cada tipo de grupo, um «habitus» específico (atitudes, concepções e disposições) a cada um deles, ou ainda, uma tipologia específica (de ações comportamentais ou cognitivas) que une (liga) de forma permanente e útil seus participantes, gerando resultados positivos; e) essas ligações, constituídas por «trocas» materiais ou simbólicas (logo, envolvendo compartilhamentos ou ações cooperativas) criam comportamentos que logicamente supõem certa proximidade (no sentido de frequência, repetitividade ou continuidade) (ORTEGA e MATOS 2013, 50).

Pensar na perspectiva do capital como instrumento que leve à superação de limite e privações, principalmente quando relacionado a 
comunidades amazônicas, é pensar na perspectiva de fortalecer sujeitos coletivos com potencial para reescrever a sua própria história, as relações e o desenvolvimento. Nessa linha de pensamento, a formulação de HELAL e NEVES (2007) evidencia o papel do capital social no combate à pobreza e na criação de sistemas sustentáveis de superação dessa pobreza, trazendo duas perspectivas a serem consideradas para isso: a macroscópica e a microscópica.

$\mathrm{Na}$ perspectiva macroscópica, o capital social se relaciona com o combate à pobreza, com a implementação de políticas públicas voltadas a incentivar a organização de associações capazes de integrar indivíduos e fortalecer a coesão comunitária. Nessa visão, o capital social seria um atributo da comunidade, e não do indivíduo. Já na perspectiva microscópica, os benefícios individuais fortalecem o capital e, consequentemente, a rede ou grupo do qual ele participa. Pensando na perspectiva amazônica, a superação de limites e privações econômicas, sociais e políticas exige uma ação que fortaleça as duas perspectivas: a macroscópica e a microscópica.

O capital social é um importante fator de desenvolvimento da organização social. Está relacionado ao empoderamento dos extrativistas e das comunidades amazônicas, ou seja, confere a «capacidade de influir nas decisões públicas» (COSTA et al., 2008, 66).

O fortalecimento da organização dos extrativistas (associação e cooperativa) decorrente de um passado, de uma luta pelo direito de manter seu modo de vida, permite pensar uma perspectiva de desenvolvimento relacionada a liberdade (SEN, 2000), em que as pessoas podem existir de forma ativa. Para BILERT et al.

Frente às décadas de lutas e dificuldades para a sociedade conquistar diversos direitos, o direito à liberdade foi sempre o mais evidenciado quando se refere a constituição social dos grupos e comunidades, atrelado aos fatores sociais, culturais e políticos. É possível aferir, então, que a liberdade favorece as normas e a confiança, o que propicia que as redes atuem constantemente comprometidas com o futuro, potencializando ações e soluções práticas para o desenvolvimento de uma determinada localidade ( BILERT et al., 2011, 33)

As comunidades localizadas às margens dos rios Purus, Ituxi e afluentes, no município de Lábrea, AM, se originaram a partir da defesa do direito à terra, portanto na defesa dos «lugares de vida das comunidades, de sua memória, de seu enraizamento econômico, social e cultural» (TEISSERENC; TEISSERENC 2014, 103). Esses aspectos são pressupostos para unir as comunidades e fazer com que elas atuem com reciprocidade. É nessa perspectiva que deve ser entendido o ca- 
pital social, dentro de uma realidade amazônica, onde a resistência ao modelo dominante faz surgir interações cooperativas, expressas nas associações comunitárias e que brotam das necessidades de defenderem o seu território e o modo de vida de ser das comunidades.

\section{Metodologia de pesquisa}

O artigo tem como objeto de estudo a Cooperativa Mista Agroextrativista do Sardinha (COOPMAS), localizada no município de Lábrea, $\mathrm{AM}^{12}$, responsável pela comercialização da produção de mais de 200 famílias.

A cooperativa tem sido, nos últimos anos, um instrumento econômico e social fundamental para o desenvolvimento das comunidades extrativistas e agrícolas do município, principalmente da região do Rio Purus e afluentes e Rio Tapauá e afluentes, onde há grande produção de castanha-do-brasil (Bertholletia excelsa), borracha (Hevea brasiliensis (HBK) e feijão-caupi (Vigna unguiculata (L.) Walp).

Fundada em 2008, a COOPMAS é parte de um processo de crescimento e ampliação das estratégias dos agricultores e extrativistas das comunidades de Lábrea, que passaram a empreender melhorias nos processos de comercialização, como o acesso a políticas públicas e financiamento da produção e comercialização; a agregar valor ao produto por meio do processamento. A cooperativa buscou novos mercados para a castanha, tanto in natura como processada. É por isso que a cooperativa é gestada no interior da Associação dos Produtores Agroextrativistas da Colônia do Sardinha (ASPACS), criada em 1997, e que ainda hoje trabalha com projetos em conjunto com as associações.

A COOPMAS surgiu para expandir o alcance geográfico da associação, que era mais limitada em relação à comercialização, assumiu as atividades da usina de beneficiamento de castanha-da-amazônia e demais atividades relacionadas ao extrativismo, além de fortalecer a organização e a produção de 15 associações de agricultores familiares e extrativistas da região. Atualmente abrange os municípios de Lábrea, Canutama e Tapauá, no estado do Amazonas, contando com 48 cooperados e atendendo mais de 200 extrativistas. A cooperativa está em pleno funcionamento, beneficiando os produtos adquiridos diretamente dos produtores locais (COSTA, 2015).

12 Em linha reta, a sede do município de Lábrea fica a 702,60 km da capital do estado do Amazonas, a cidade de Manaus. 
Em 2009, a COOPMAS passou a ser a gestora da usina de beneficiamento da castanha, em evento inaugurado com a presença do governador do estado do Amazonas ${ }^{13}$.

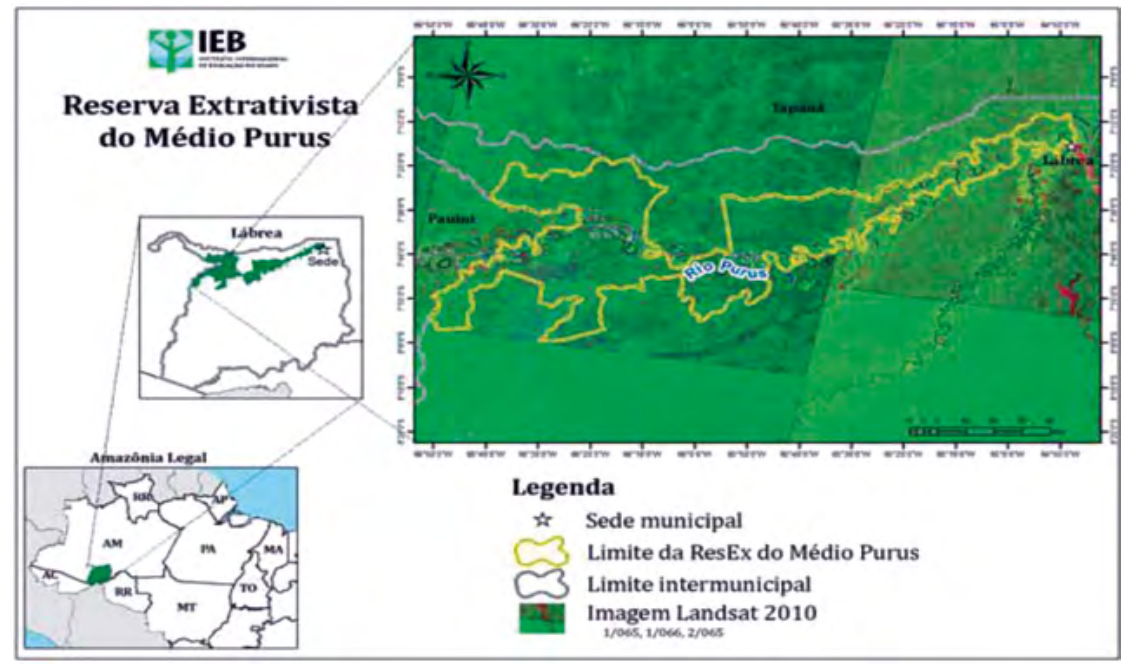

Fonte: ALEIXO, J (IEB) 2011, 14.

Figura 1

Localização do Rio Purus, onde encontra-se a maior parte dos associados da Cooperativa Mista Agroextrativista do Sardinha (COOPMAS)

O estudo é relevante porque possibilita fazer análise dos seguintes fatores: a COOPMAS é formada e administrada por extrativistas e vem alcançando êxito em seus objetivos e missão, além de conquistar novos mercados fora da região. Por intermédio da cooperativa os agricultores e extrativistas puderam acessar programas governamentais e financiamento, cujos benefícios só foram possíveis alcançar por meio das parcerias formalizadas com órgãos governamentais, entidades comunitárias e sociais. As parcerias são essenciais para desencadear um processo de ampliação e diversificação da produção extrativa e agrícola, assim como para o desenvolvimento das comunidades rurais.

Os dados e as informações contidos no presente texto foram coletados a partir de pesquisa bibliográfica relacionada à temática no âm-

13 Nesse período, o governador era Eduardo Braga, que atualmente é senador da república. 
bito estadual e local, e por meio de entrevistas com pessoas-chaves da comunidade: extrativistas, agentes públicos e lideranças da comunidade e da cooperativa.

Foram realizadas entrevistas estruturadas e semiestruturadas. O roteiro continha questões abertas e fechadas. Com base em GIL (2002), esse método foi aplicado na interação pesquisador e entrevistado, com o propósito de descrever as características da atividade ou processos abordados na pesquisa. Essa técnica permitiu melhor caracterização da infraestrutura, produção, organização, comercialização, acesso a programas e projetos governamentais, entre outros.

\section{Resultados}

\subsection{A origem e a importância da organização da cooperativa}

A história do surgimento do município de Lábrea, localizado no sul do estado do Amazonas, está ligada à exploração dos seus recursos naturais, principalmente às "drogas do sertão», a partir do século XVII. Os principais recursos explorados nos primórdios do município foram: cacau, salsaparrilha e canela, produtos altamente apreciados na Europa.

No século XIX, com a corrida pela borracha, o coronel Labre ${ }^{14}$ se estabeleceu na região do Purus, onde com «uma leva de migrantes nordestinos, começa a exploração do látex. A área logo se tornou uma importante porta de entrada para as florestas ricas em seringueiras que se estendiam até o Acre» (ALEIXO 2011, 13).

Com a borracha, a região passou a abrigar «a vinda de mão de obra para os seringais, essa situação acarretou o aumento populacional significativo sobretudo de pessoas oriundas de regiões do nordeste brasileiro» (COSTA, MENEZES 2015, 75).

O ingresso dos migrantes na região onde se encontra o município de Lábrea fortalece a economia da borracha e, como consequência, o poder dos «seringalistas», "coronéis de barranco» ou «patrões», os quais controlavam todas as dimensões da vida dos extrativistas do Purus. Segundo NODA (2008, 50), o poder dos patrões chegou ao ponto de não permitir que os seringueiros cultivassem até mesmo para

14 Em dezembro de 1871, chegou a maior leva de maranhenses, sob o comando do Coronel Antônio Rodrigues Pereira Labre, instalando-se às margens do Rio Purus, na terra firme de Amaciari, que passa a denominar-se Lábrea. In: Família Labre. «Mais informações a respeito de Labrea-AM.» Família Labre. http://familialabre.blogspot.com (acesso Mai 25,2019). 
autoconsumo. Caso algum agricultor ousasse praticar a agricultura, a metade teria que ser dada ao patrão. Pois, para este, o importante era manter a produção extrativista. Ele entendia que «o tempo consumido em caça e pesca se furta da produção» (REIS,1953, 107) e sua resistência em deixar os extrativistas cultivar a roça estava relacionada "a possíveis lucros obtidos com a venda de gêneros alimentícios». A ideia era que os extrativistas não pudessem desviar o foco e que mantivessem os esforços nos produtos que garantissem saldos positivos ao patrão: a borracha, a castanha e outros (TEIXEIRA, 2009, 85).

$\mathrm{Na}$ relação do extrativista com o seringalista (que era o patrão e/ ou o atravessador), a dívida sempre teve uma função especial e essencial, em que não existia qualquer compromisso formal. A dívida, para o seringueiro, representava a necessidade e o dever de «saldá-la; para o patrão (seringalista) era o direito de usar métodos de persuasão para manter o seringueiro a seu serviço. Enquanto o patrão necessitava de mão-de-obra para suas estradas de seringa, o freguês depende dos aviamentos do patrão para a sua sobrevivência» (CHEROBIN, 1983, 102). Para COSTA e MENEZES , a consequência da dominação nos seringais, castanhais e fazendas era produzir uma estrutura que permeasse diversas estruturas e espaços de poder.

"As estruturas que se formaram através do poder dos patrões da borracha, cujas atividades foram, em certa medida, convertidas ou transferidas a outros patrões de castanhais ou fazendas, traduziramse em domínio do poder político na esfera pública dos municípios do Purus. Não raro, prefeitos e vereadores dos municípios da região revestiam-se da figura do patrão, reproduzindo na administração pública as relações de poder e a dominação vivenciadas no interior dos seringais e castanhais. A relação de controle e dominação se reproduz em diversos níveis, inclusive no espaço urbano desses municípios que se encontra simbolicamente marcado pelos patrões e coronéis da borracha que continuam dando seus nomes às ruas, praças e bairros das cidades. Não raro, prefeitos e vereadores são os mesmos patrões que promoveram massacres e expulsões dos povos indígenas de seus territórios». (COSTA e MENEZES 2015, 76)

O fortalecimento das comunidades extrativistas de Lábrea é consequência da necessidade de elas permanecerem e resistirem aos avanços em seus territórios e degradação de sua principal fonte de reprodução social, econômica e cultural: a diversidade socioambiental da região. Esse processo comunitário fez com que as comunidades passassem a buscar com luta, resistência e organização a emancipação ou a superação das privações (SEN, 2010). Essas ações tiveram forte apoio das 
entidades de mediação ${ }^{15}$, como a Comissão Pastoral da Terra (CPT), o Conselho Nacional dos Seringueiros (CNS), o Instituto de Estudos Brasileiros (IEB), entres outras. Essas organizações promoviam intenso trabalho de formação e organização por meio de visitas periódicas, encontros, intercâmbios e cursos de capacitação.

As reuniões e os encontros possibilitaram a troca de experiências entre comunitários e lideranças, que passaram a fortalecer as organizações comunitárias e a criar ações voltadas à defesa do direito de utilização do seu território historicamente habitado. Também desenvolviam ações para a melhoria das condições socioeconômicas e o bem-estar das comunidades.

As comunidades e organizações tiveram como um dos principais objetivos a emancipação das comunidades extrativistas do jugo dos patrões, que através do aviamento dominavam e controlavam todas as atividades produtivas dos agricultores, numa relação de exploração e espoliação total do trabalho dos extrativistas.

Estudo de NODA (2008) identificou a existência de 21 organizações formais e 10 informais no município, o que significa um alcance de 2.606 extrativistas, agricultores e pescadores atingidos diretamente e, aproximadamente, 7.818 indiretamente, o que representa $58 \%$ da população rural do município, em $2010^{16}$ (Atlas do desenvolvimento humano, 2010).

Essas organizações passaram a incidir diretamente sobre sua realidade, articulando atores locais, regionais e nacionais, estabelecendo processos de intercâmbio, negociações e acordos capazes de impactar diretamente no desenvolvimento das comunidades. Segundo ALEIXO $(2011,36)$, "encontravam-se nas margens do Purus coordenadores de comunidades religiosas ou associações comunitárias», que nem sempre eram «formalizadas, ou seja, registradas em cartório, mas demonstravam a vontade de se organizar e enfrentar os problemas existentes naquelas comunidades».

A existência de organizações comunitárias, associadas a uma conjuntura de intensa defesa do meio ambiente, inclusive com o enraizamento de muitas organizações não governamentais na região amazônica, foi essencial para o enfrentamento dos desafios da dé-

15 Entendemos como instituição ou entidade mediadora a que «ajuda as partes envolvidas em conflitos na procura de uma solução compatível para os interessados» (SOUSA, 2002, 19).

16 Em 2010 viviam, no município, 37.701 pessoas, sendo que a população rural era de 13.494 , o que representava $35,79 \%$ da população do município (Atlas do desenvolvimento, 2010). 
cada de 1990, quando o sul do Amazonas passou a fazer parte da fronteira agrícola e dos planos da implantação de projetos de exploração da região para empreendimentos agropecuários. COSTA e MENEZES $(2015,77)$ entendem que o conflito resultante desse processo fez com que aumentassem as " lutas pela demarcação de Terras Indígenas e a criação de novas modalidades de Unidades de Conservação como as Reservas Extrativistas-RESEX e as Reservas de Desenvolvimento Sustentável-RDS». Para MENEZES (2011, 131), a ação das ONGs «ambientais e a explosão de territorialidades» foram os fatores que redefiniram o "perfil político-territorial da região». Foram criadas unidades de conservação federal e as terras indígenas foram reconhecidas. No município há quatro unidades de conservação federal $^{17}$ ocupando um território de 3.695 .430 ha, o que representa 54\% do total; e as terras indígenas "somam $19 \%$ do total de sua área e a maioria delas foi demarcada entre os anos de 1991 ao ano 2000» (FRANCO, 2011, 151).

A criação da unidade fez com que as lideranças passassem a pensar estratégias de ação para além das comunidades e localidades. A unidade passou a ser o espaço pensado por todas as comunidades. Criou-se uma entidade supracomunitária: a Associação dos Trabalhadores Agroextrativistas do Médio Purus (ATAMP), criada em 2005, e chamada de «entidade mãe», que envolveu 300 lideranças das mais diversas comunidades das unidades de conservação, como instrumento de gestão e organização das comunidades que habitam a unidade de conservação.

A articulação entre as comunidades e as ações voltadas para garantir a manutenção de seus direitos territoriais promoveram o surgimento e o fortalecimento de um ambiente de cooperação e confiança entre agricultores, extrativistas e indígenas.

Nesse ambiente, marcado por processos organizativos, mobilizações e conquistas, é criada em 1997 a ASPACS para ser o instrumento organizativo de agricultores despejados com a demarcação das terras indígenas (COSTA, 2015). Esses agricultores foram assentados na comunidade do Sardinha e, inicialmente, tentaram manter a sua atividade anterior: o cultivo de cana-de-açúcar, produto que era comercializado para a fábrica da Coca-Cola, porém a baixa fertilidade do solo fez com que essa atividade não prosperasse e os agricultores buscassem outras alternativas (COSTA, 2015). Com o apoio do Instituto de Des-

17 Essas unidades são: Resex Médio Purus, Flona Iquiri, Resex do Ituxi e Parna Mapinguary (MPF, 2013, p.8). 
envolvimento Agropecuário e Florestal Sustentável do Estado do Amazonas (Idam), desenvolveram-se iniciativas produtivas, como avicultura, pesca e manejo do pirarucu e o extrativismo da borracha, de óleos vegetais e da castanha, como também da produção de feijão-de-praia18 (COSTA, 2015). Com o tempo, os agricultores agroextrativistas da Colônia do Sardinha abandonaram a cana-de-açúcar e passaram a introduzir outras culturas, diversificando a pauta da agricultura familiar no município de Lábrea.

Em 2009 nasce a COOPMAS, cooperativa que passou a organizar a produção e a comercialização dos produtos dos associados, sendo o principal a castanha-do-brasil, seguido da borracha e do feijão-depraia. Ela também passou a gerenciar a usina de beneficiamento de castanha-do-brasil| ${ }^{19}$.

A capacidade organizativa das comunidades influenciou fortemente os extrativistas, que passaram a vender a produção somente para a cooperativa, num processo de crescente fidelização. A organização social levou os extrativistas e agricultores a se distanciarem dos seringalistas, patrões e comerciantes. A cooperativa passou a ser referência, sendo apoiada por órgãos como a Secretaria de Produção, a Agência de Fomento do estado e outros.

Em 2015, a cooperativa obteve a aprovação do projeto de ampliação e mecanização da indústria de beneficiamento de castanhada-amazônia pela Fundação Banco do Brasil, passando de 1.000 kg de amêndoas processadas para $3.000 \mathrm{~kg} / \mathrm{dia}$.

Na perspectiva de diversificar a produção e melhorar a renda dos extrativistas, a cooperativa firmou parceria com a Prelazia para a construção de uma agroindústria de beneficiamento de polpa de frutas, ocasião em que será possível beneficiar o açaí, que é um dos principais produtos extrativistas do município. Com a agroindústria, a cooperativa irá disponibilizar polpa de açaí para o mercado interno, pois o fruto é muito apreciado no município e, no âmbito externo do município, é matéria-prima para a indústria de refrigerante e bebidas energéticas. Em 2016, com aporte do Fundo de Promoção Social (FPS), administrado pelo governo estadual, a agroindústria ampliou a sua capacidade produtiva.

18 O cultivo do feijão-de-praia no município de Lábrea ocorre durante o período de seca do Rio Purus.

19 A usina passou a funcionar em março de 2009. A instalação aconteceu mediante parceria entre governo do estado, Ministério da Agricultura, Ministério da Integração Nacional, governo do município, Fucapi e Organização das Cooperativas do Brasil (OCB). 
A capacidade de articulação da associação e da cooperativa com outras organizações do município possibilitou, em 2016, que as comunidades ribeirinhas, por meio do Serviço Florestal Americano e do ICMBlo Nacional, recebessem botes de alumínio para acoplar o motor rabeta, doado pela Operação Amazônia Nativa (Opan) por meio do Projeto Petrobrás Ambiental. Esse equipamento facilitou o transporte da família e da produção, como também contribuiu para a redução do tempo de deslocamento entre a comunidade e a área de coleta da castanha.

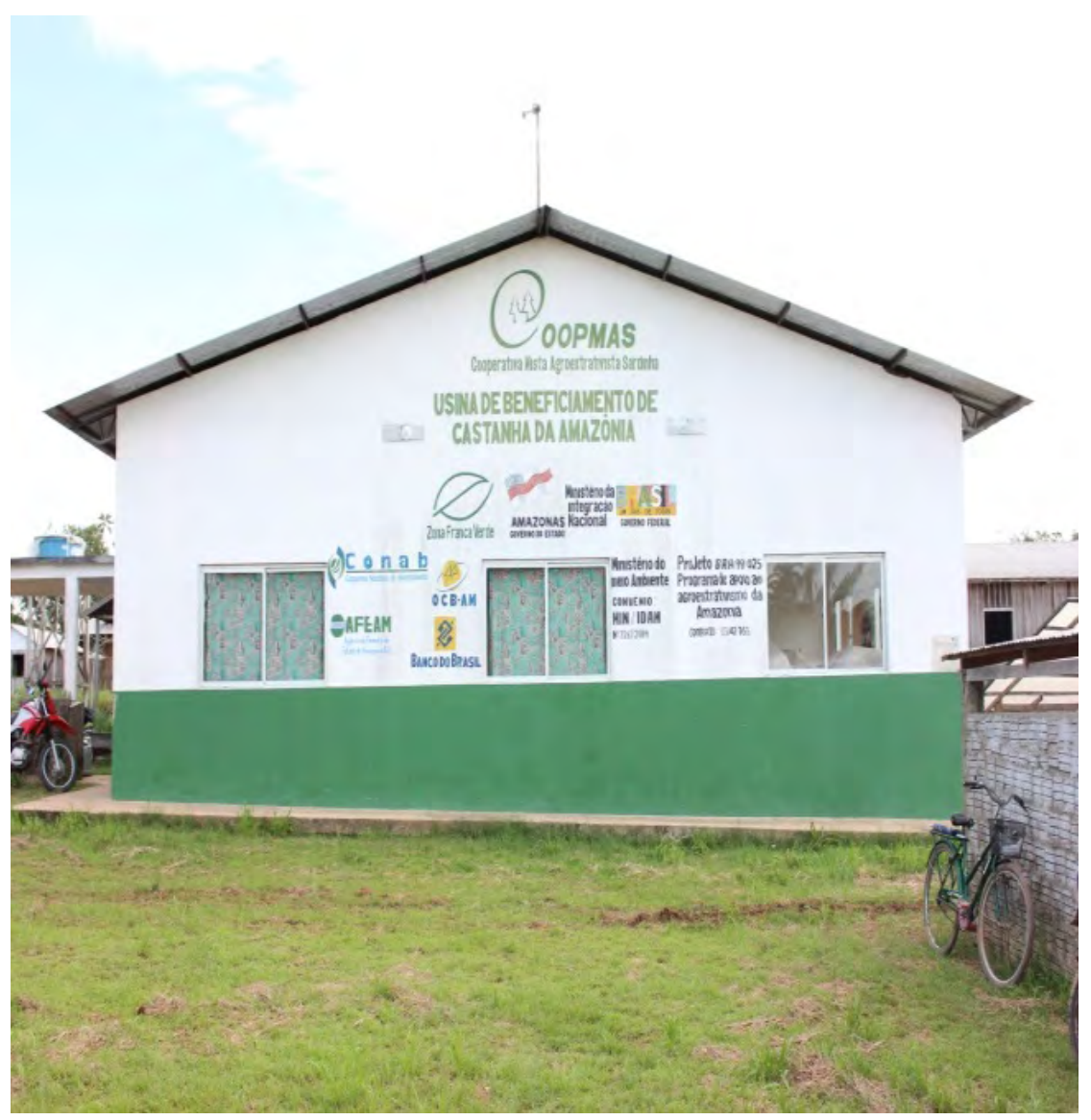

Fonte: COSTA (2018), registro da pesquisa de campo.

Figura 2

Cooperativa Mista Agroextrativista do Sardinha (COOPMAS) 


\subsection{Impactos econômicos da cooperativa na comercialização dos produtos extrativistas}

Desde a organização da cooperativa é possível observar importantes mudanças na comercialização dos produtos das comunidades extrativistas do Purus. O aviamento dá lugar ao crédito para a coleta da castanha, oriundo de política pública, viabilizado com o apoio da Agência de Fomento do Estado do Amazonas (Afeam). Isso significa autonomia no desenvolvimento do extrativismo, ou seja, os extrativistas não necessitam mais se vincular ao patrão ou comerciante. Quando não havia crédito, os extrativistas, no início da safra, pelo aviamento, tornavam-se reféns, pois necessitavam de alimentos, equipamentos e utensílios para ir à coleta. Desta forma, possibilitando o acesso ao crédito, a cooperativa quebra um dos pilares do poder dos patrões, comerciantes e atravessadores.

A cooperativa passou a comercializar os produtos agrícolas e extrativistas (vegetal e animal), garantindo preço adequado e bom retorno aos cooperados. A importância da cooperativa pode ser observada na comercialização dos produtos, como a borracha, o pirarucu, a castanha e o feijão.

Em 2016, o quilo da borracha era adquirido pelo atravessador ao preço de $R \$ 2,00$. A cooperativa pagava $R \$ 3,50$ a seus associados, um preço $75 \%$ superior ao do atravessador, que anteriormente adquiria a produção de 250 produtores de látex ao longo do Rio Purus.

A quantidade de pirarucu de manejo, oriundo das unidades de conservação do município, no período de 2013 a 2016, alcançou uma produção de $121.273,50 \mathrm{~kg}$. Essa produção permite a manutenção do estoque e a conservação da espécie e possui cota autorizada pelo Instituto Brasileiro do Meio Ambiente e dos Recursos Naturais Renováveis (Ibama). Porém, a força do atravessador e a ausência de uma política de valorização da atividade faziam com que o quilo desse peixe nobre da Amazônia fosse adquirido pelo atravessador ao preço de $R \$ 3,00$. Com a cooperativa, os extrativistas conseguiram acessar o mercado institucional, o Programa de Aquisição de Alimento, e assim passaram a comercializar o produto ao preço de $\mathrm{R} \$ 7,00$, que é $133 \%$ superior ao preço do atravessador.

Outro produto que alcançou preço melhor, quando comercializado pela cooperativa, foi o feijão-caupi. Esse produto agrícola era comprado pelos atravessadores a $\mathrm{R} \$ 0,50$ o quilo. Com a cooperativa o preço alcançou $R \$ 1,07$ o quilo, já que a COOPMAS pode comercializar diretamente com o mercado institucional, no caso o Programa de Aquisição de Alimentos da Companhia Nacional de Abastecimento (Conab), uma alta de $104 \%$ em relação ao preço pago pelos atravessadores. 
A contribuição para a melhoria do preço dos produtos oriundos do extrativismo e dos cultivos das comunidades do Purus também tem reflexo na quantidade adquirida de castanha-do-brasil, um dos principais produtos da cooperativa. O município de Lábrea é um dos principais produtores de castanha-do-brasil do estado do Amazonas. Considerando o período de 2010 a 2016, o município produziu em média mil toneladas por ano. Entre 2010 e 2016, a cooperativa já adquiriu 1.044,9 t de 450 extrativistas em 52 comunidades. Essa produção é comercializada nos mercados regionais e nacionais, principalmente para a região Sudeste e Sul do Brasil. Uma parte da produção atende o mercado do Amazonas e outra é enviada para os estados do Rio de Janeiro e Rondônia, e 10\%, ao mercado institucional, principalmente para a merenda escolar.

A cooperativa, além de trazer benefícios na questão da organização dos extrativistas e agricultores, funciona como reguladora de preço na comercialização dos produtos, como mostra o Quadro 1. O preço oferecido pela cooperativa faz com que os atravessadores também elevem os seus preços, o que permite melhor ganho aos extrativistas na comercialização dos produtos.

Em 2012, o preço da lata de castanha pago pelo atravessador era $20 \%$ menor que o da cooperativa. Essa tendência continuou até 2017, quando o atravessador equiparou o preço pago ao da cooperativa. É um avanço na melhoria dos ganhos dos agricultores e coletores, entretanto ainda não constitui uma situação ideal, mas a existência das cooperativas permite aos extrativistas o poder de barganha e a comercialização da sua produção a um preço melhor. A melhoria de preço, segundo TOMASI $(2016$, p.7), ocorre porque a COOPMAS, «para honrar seus contratos com compradores externos, define um piso mínimo de preço de compra pela lata de castanha». Uma lata equivale a $10 \mathrm{~kg}$. Quando a cooperativa «fixa preços», estes "puxam» para cima os valores comerciais praticados pelos atravessadores».

\section{Quadro 1}

Preço de compra da castanha-do-brasil, comparação entre o preço praticado pela COOPMAS e o preço pago pelos «patrões e atravessadores»

(em reais)

\begin{tabular}{lcccccc}
\hline \multicolumn{1}{c}{ Comprador } & 2012 & 2013 & 2014 & 2015 & 2016 & 2017 \\
\hline COOPMAS & 20,00 & 16,00 & 36,00 & 26,00 & 46,00 & 50,00 \\
Patrão e atravessador & 16,00 & 15,00 & 30,00 & 20,00 & 40,00 & 50,00 \\
\hline
\end{tabular}

Fonte: coleta de campo, organizado pelos autores, 2017. 
A cooperativa é um instrumento de apropriação de riqueza e valores pelos extrativistas, evidenciando que a organização social e econômica é uma alternativa viável para a superação das condições de pobreza de muitas comunidades no interior da floresta. A cooperativa melhora o preço, dinamiza a produção, contribui para a diversificação dos cultivos, gera renda, cria e mantém postos de trabalho e também emancipa o extrativista do jugo dos comerciantes e atravessadores. Para COSTA (2015, p. 244), fazendo menção à castanha-do-brasil, a importância da cooperativa para as comunidades está relacionada à «compra da castanha diretamente do produtor» ao "acompanhamento logístico» e ao processamento e comercialização no âmbito estadual e nacional.

Além do impacto junto aos extrativistas, na compra e comercialização da produção, a cooperativa gera de modo temporário, no período da safra da castanha, 70 contratações diretas de colaboradores para o processo de beneficiamento, durante mais de seis meses por ano. Até 2015, a cooperativa manteve quatro funcionários permanentes e em 2017 esse número passou para sete. Tal ação impacta diretamente na economia, movimentando o comércio local e ampliando a demanda por produtos e serviços no município.

As redes são um dos pilares que sustentam a ação coletiva das comunidades extrativistas do Médio Purus, em Lábrea. Essas redes, forjadas no processo das lutas pela manutenção da posse da terra, pelas melhorias econômicas e sociais, constituem forte instrumento de dinamização socioeconômica da vida dos extrativistas do Purus. Para SILVA et al. (2015, p. 388), o fato de a COOPMAS ser uma instituição com grande capacidade de se articular com instituições "governamentais e não governamentais» facilita o «acesso a políticas públicas» e a novos mercados, criando um ambiente de cooperação e fortalecimento da iniciativa.

Mesmo com todos os ganhos com a cooperativa, a estrutura ainda é pequena diante das necessidades de um grande número de agricultores e extrativistas da região. Uma relação entre produção municipal e quantidade adquirida pela cooperativa mostra que a organização dos extrativistas tem capacidade de compra e de processamento de apenas $17 \%$ da produção total no período de 2010 a 2016. A pesquisa de TOMASI (2016) mostra que os atravessadores e comerciantes são 4,6 vezes mais capitalizados do que a COOPMAS, o que faz com que grande quantidade de castanha do Amazonas deixe de ser um produto vol- 
tado a gerar desenvolvimento e bem-estar nas comunidades e no próprio município de Lábrea. ${ }^{20}$

Os desafios para tornar a castanha e outros produtos extrativistas uma alternativa que impulsione o desenvolvimento e propicie o bemestar das comunidades são muito grandes. Porém, os ganhos obtidos pela cooperativa comprovam a tese de que a superação da pobreza e a sustentabilidade ambiental em comunidades amazônicas somente será alcançada com o «empoderamento» da comunidade, mediante o fortalecimento de suas organizações.

\section{Considerações finais}

O processo organizativo que envolveu as comunidades extrativistas de Lábrea mostra que a manutenção e conservação da Amazônia, por meio da exploração sustentável, passa pelo fortalecimento socioeconômico. Entre as diversas estratégias de conservação e preservação da floresta, associadas ao desenvolvimento e ao bem-estar das comunidades extrativistas, a organização das comunidades para a formação de sujeitos ativos, emancipados e sujeitos de sua própria história, é a que tem se mostrado a mais eficaz para a construção da autonomia social e econômica.

A cooperativa e as associações se originaram de um processo de educação para a cidadania, autonomia e participação, implementado em períodos anteriores, com mediação de instituições locais e regionais. Sem esse processo educativo continuado, que forma para a participação, dificilmente teria acontecido o processo de formação de associações e cooperativa. A sobrevivência e o cumprimento da função social dessas formas associativas também dependem de uma prática de gestão que propicie aos agricultores e extrativistas a participação efetiva, democrática e responsável, com foco na autonomia para o desenvolvimento. A participação é um elemento vital para a sobrevivência das instituições.

O exemplo da COOPMAS mostra que o apoio governamental é muito importante, porém ela só produz frutos quando encontra res-

20 Para chegar a essa razão, TOMASI $(2016$, p.9) faz uma relação entre «o montante de investimento em capital de giro para viabilização da atividade castanheira em Lábrea - mostrada anteriormente- entre o Setor do Aviamento e a COOPMAS (7 milhões de reais versus 1,5 milhões de reais), que alcança uma razão de 4,6. Ou seja, o setor privado é 4,6 vezes mais capitalizado do que a COOPMAS no mercado da castanha de Lábrea». 
sonância em uma base organizativa social sólida, enraizada, cujo grupo social beneficiário tem na organização o meio capaz de atingir seus objetivos coletivos. A política pública, para ser efetiva, precisa ter a participação dos «beneficiários» e ser acompanhada por uma série de ações de educação e formação. Então, fica cada vez mais evidente que há a necessidade de superar estágios, e é preciso, com organização política e econômica, que venha o crescimento das habilidades técnicas específicas, porém sempre mantendo o espírito coletivo na cooperativa. 0 fortalecimento das associações locais e dos associados precisa fazer parte da estratégia de ação da COOPMAS, já que a atuação econômica principal dessa cooperativa está focada na aquisição e no processamento da castanha-do-brasil, onde há forte ação monopolizadora de grupos centenários, como é o caso dos Mutram, que é economicamente forte e permeia com desenvoltura o meio político na região.

As informações e dados relacionados à presença da cooperativa em Lábrea mostram que essa instituição tem o potencial de garantir aos associados a possibilidade de avanços econômicos e sociais. E como organização coletiva, permite aos extrativistas superarem fragilidades como: dificuldade de acesso a crédito, transporte, canais de comercialização e acesso a políticas públicas.

A cooperativa, articulada com as associações de agricultores da região, tem papel econômico e social muito importante na melhoria de vida de um grupo significativo de famílias do município e região, adquirindo produtos a um valor justo, aumentando a renda das famílias, processando a castanha e comercializando parte dela. Aliada a isso, sob o aspecto social, a atividade de processamento permite, mesmo que temporariamente, a criação de postos de trabalho para um grupo significativo de pessoas. Os agricultores e coletores de castanha não estão mais expostos à espoliação dos atravessadores da mesma forma que antes da formação das associações e da cooperativa. A cooperativa regula os preços dos produtos para cima, e mesmo os agricultores e extrativistas não associados acabam se beneficiando dessa ação.

É fundamental entender o papel social da cooperativa no processo organizativo e econômico das comunidades e seu potencial na comercialização e processamento dos produtos e, de modo especial, da castanha e de outros produtos do extrativismo, que têm um papel, diríamos, essencial para o desenvolvimento e a sustentabilidade da Amazônia. A ação da cooperativa constitui um capital intangível no município de Lábrea, porém o município ainda não possui um conjunto de organizações capaz de implementar inovações para resolver os problemas coletivos. Esse é um grande desafio para a consolidação de um desenvolvimento endógeno no município de Lábrea e região do Purus. 
Portanto, a cooperativa constitui importante instrumento de desenvolvimento para a superação de privações, construindo sujeitos coletivos, com forte incidência política, social e econômica capazes de garantir o bem-estar e a sustentabilidade ambiental das comunidades amazônicas.

\section{Referências bibliográficas}

ABRAMOVAY, Ricardo. 2000. O capital social dos territórios: repensando o desenvolvimento rural. Economia Aplicada, 379-397. São Paulo: Economia Aplicada.

ABRAMOVAY, Ricardo e Luiz Carlos BEDUSCHI FILHO. 2003. "Desafios para a gestão territorial do desenvolvimento sustentável no Brasil». Em Anais do XLI Congresso Brasileiro de Economia e Sociologia Rural. Juiz de Fora: Sober.

ALBAGLI, Sarita e Maria Lucia MACIEL. 2002. Capital social e empreendedorismo local. Rio de Janeiro: UFRJ/IE-RedeSist-FINEP-SEBRAE.

ALEIXO, Josinaldo. 2011. Memorial da luta pela Reserva Extrativista do Médio Purus em Lábrea-AM: registro da mobilização social, organização comunitária e conquista de cidadania na Amazônia. Brasília: Associação dos Trabalhadores Agroextrativistas do Médio Purus e Instituto Internacional de Educação do Brasil.

ALMEIDA, Alfredo Wagner Bueno de. 2008. Antropologia dos Archivos da Amazônia. Rio de Janeiro: Casa 8.

ARAMBURU, Mikel. 1994. «Aviamento, modernidade e pós-modernidade na Amazônia». Revista Brasileira de Ciências Sociais, no. 25.

ATLAS DO DESENVOLVIMENTO: LÁBREA. 2010. Acesso em 15 de maio de 2019. http://www.atlasbrasil.org.br/2010/pt/home/.

BATISTA, Djalma. 2007. O Complexo da Amazônia: análise do processo de desenvolvimento. 2. ${ }^{a}$ ed. Manaus: Valer, Edua e Inpa.

BEDUSCHI FILHO, Luiz Carlos e Ricardo ABRAMOVAY. 2004. "Desafios para o desenvolvimento das regiões rurais». Nova Economia 14, no. 3: 35-70.

BENCHIMOL, Samuel. 2009. Amazônia: formação social e cultural. Manaus: Valer.

BILERT, Vania Silva de Souza, Miguel Ângelo PERONDI, André ALVES PEREIRA e Simão TERNOSKI. 2011. "A contribuição do capital social para o desenvolvimento local». Ciências Sociais Aplicadas em Revista 11, no. 21: 29-42.

BOURDIEU, Pierre. 1998. Escritos de educação. Petrópolis: Vozes.

BOURDIEU, Pierre. 2005. "O campo econômico». Revista Política e Sociedade: 15-57.

CARDOSO, Ciro Flamarion. 1984. Economia e Sociedade em áreas coloniais periféricas: Guiana Francesa e Grão-Pará 1750 e 1817. Rio de Janeiro: Graal.

CHEROBIM, Mauro. 1983. Trabalho e comércio nos seringais, 101-107. São Paulo: Perspectivas. 
COLEMAN, James S. 1990. Foundations of Social Theory. Cambridge: Harvard University Press.

COLLIS, Jill e Roger HUSSEY. 2005. Pesquisa em administração. 2. ${ }^{a}$ ed. São Paulo: Bookman.

COSTA, Ivana, Ana Cecília FEITOSA VASCONCELOS, Elizabeth DE OLIVEIRA ANDRADE, Gesinaldo ATAÍDE CÂNDIDO e Isabela ASSIS GUEDES ROSAS. «Capital social como instrumento para viabilização do desenvolvimento regional: estudo de caso no Cariri Paraibano». G\&DR 4, no. 2: 58-80.

COSTA, Jemima Ismael da. 2015. "Associativismo e cooperativismo em uso de recursos naturais da Amazônia: castanha-do-Brasil» Em Anais do Workshop de Pesquisa e Agricultura Familiar: Fortalecendo a Interação da Pesquisa para Inovação e Sustentabilidade, 339-348. Manaus: Embrapa.

COSTA, Willas Dias da Costa e Thereza C. CARDOSO MENESES. 2015. «Antigas e novas dinâmicas de poder e território no Médio Purus/AM». Textos \& Debates, no. 26: 73-84.

FALCÓN, Carmen Esther y FUENTES, Juana. 2017. «La participación de las cooperativas en el desarrollo urbano sostenible». REVESCO. Revista de Estudios Cooperativos, 125: 89-108. doi: http://dx.doi.org/10.5209/ REVE. 57063

FAMÍLIA LABRE. 2019. «Mais informações a respeito de Lábrea-AM.» Família Labre. Acesso em 25 de maio de 2019. http://familialabre.blogspot.com

FERREIRA, Ericka Sales e Vera Lúcia SALAZAR PESSÔA. 2012. «Capital social e desenvolvimento territorial: uma abordagem teórica-conceitual». CampoTerritório: revista de geografia agrária 7, no. 14: 1-330.

FONSECA, Antônio Ângelo Martins. 2005. Instituição e desenvolvimento territorial. O desempenho municipal após a descentralização. Feira de Santana: UEFS.

FRANCO, Marcelo Horta Messias. 2011. «Novas configurações territoriais no Purus indígena e extrativista». Em Álbum Purus. Manaus: Edua.

GIDDENS, Anthony. 2001. A terceira via: reflexões sobre o impasse político atual e o futuro da social-democracia. Rio de Janeiro: Record.

GIL, Antônio Carlos. 2002. Como elaborar projetos de pesquisa. 4. ${ }^{a}$ ed. São Paulo: Altas.

HECK, Egon; Francisco LOEBENS; Priscila D. CARVALHO. 2005. «Amazônia indígena: conquista e desafios». Estudos Avançados 19, no. 53: 237-255.

HELAL, Diogo Henrique e Jorge Alexandre BARBOSA NEVES. 2007. Superando a pobreza: o Papel do Capital Social na Região Metropolitana de Belo Horizonte. Rio de Janeiro: Cadernos EBAPE. BR.

HOMMA, Alfredo Kingo Oyama e Antonio José ELIAS AMORIM DE MENEZES. 2014. "Avaliação de uma agroindústria beneficiadora de castanhado-pará na microrregião de Cametá, Estado do Pará». Em Extrativismo vegetal na Amazônia: história, ecologia, economia e domesticação. Brasília: Embrapa.

LINK, Rogério Sávio. 2017. «Os apurinã e a última fronteira do estado brasileiro». Fronteiras: Revista de História: 11-42. 
LIRA, Talita de Melo e Maria do Perpétuo Socorro RODRIGUES CHAVES. 2016. Comunidades ribeirinhas na Amazônia: organização sociocultural e politica: 66-76. Campo Grande-MS: Interações.

LONDERO, Márcia. 2009. Ciências Sociais nas organizações. Curitiba: IESDE Brasil S.A.

LÓPEZ, Josune. 2019. "The promotion of both decent and green jobs through cooperatives». Boletín de la Asociación Internacional de Derecho Cooperativo, 54: 115-129. doi: http://dx.doi.org/10.18543/baidc-542019pp115-129

MEDINA, Analaura y FLORES, Uziel. 2018. "Estudio dialéctico de la economía social». Boletín de la Asociación Internacional de Derecho Cooperativo, 52: 73-106. doi: http://dx.doi.org/10.18543/baidc-52-2018pp73-106

MEIRELLES, Thomaz. 2016. Workshop do pirarucu. Acesso em: 26 de novembro de 2017. http://thomazrural.com.br/2016/07/09/sera-que-o-workshop-do-pirarucu-lembrou

MENEZES, Thereza. 2011. "Dois destinos para o Purus: desenvolvimentismo, socioambientalismo e emergência dos povos tradicionais no sul do Amazonas». Em Álbum Purus, 131-152. Manaus: Edua.

MINISTÉRIO PÚBLICO FEDERAL. 2013. Relatório da 3. ${ }^{a}$ edição do Projeto MPF nas Comunidades amazônicas («MPF na Comunidade»). Lábrea-AM: MPF.

MIRANDA, Ricardo Nunes. 2013. Zona Franca de Manaus: desafios e vulnerabilidades. Textos para Discussão, 126. Brasília: Núcleo de Estudos e Pesquisas do Senado Federal.

NASCIMENTO, Maria das Graças. 1998. "Migrações nordestinas para a Amazônia». Revista de educação, cultura e meio ambiente: 1-13.

NODA, Eliana Aparecida do Nascimento. 2008. «Políticas agrícolas e ambientais no Baixo e Médio Purus-AM». Dissertação de Mestrado, Curso de Ciências do Ambiente e Sustentabilidade na Amazônia, Universidade Federal do Amazonas.

ORTEGA, Antônio César e Vitor Alberto MATOS. 2013. "Território, desenvolvimento endógeno e capital social em Putnam e Bourdieu». Revista Politica \& Sociedade: 35-60.

PUTNAM, Robert. 1993. Comunidade e democracia: a experiência da Itália moderna. Rio de Janeiro: FGV.

PUTNAM, Robert. 2006. Comunidade e democracia: a experiência da Itália moderna. Rio de Janeiro: FGV.

PUTNAM, Robert. 1993. The prosperous comunity: social capital and public life. The American Prospect n. ${ }^{\circ} 13$. Cambridge: Springer. Acesso em 20 de maio de 2019. http://epn.org/prospect/13/13putn.htlm

REIS, Arthur Cézar Ferreira. 1953. O seringal e o seringueiro. Rio de Janeiro: Ministério da Agricultura.

RIBEIRO, Lilian Lopes e Jair ANDRADE DE ARAÚJO. 2018. "Capital social e pobreza no Brasil». Revista de Economia Politica 38, no. 4 (153): 749-765.

ROUTLEDGE, Bryan e Joachim AMSBERG. 1996. Endogeneous social capital. Pittsburgh: Carnegie Mellon University. 
SANTOS, Valcir Bispo. 2007. «Capital Social em áreas de Acordos de Pesca na Amazônia Oriental: articulações entre escalas e aspectos institucionais e organizativos nos processos de aprendizagem e inovações de pescadores artesanais ribeirinhos». Trabalho apresentado nos Anais do II Seminário Nacional Movimentos Sociais, Participação e Democracia, UFSC, Florianópolis.

SEN, Amartya. 2010. Desenvo/vimento como liberdade. São Paulo: Companhia das Letras.

SIMONI, Jane. 2010. A. Revitalização do extrativismo: práticas de economia solidária e sustentabilidade. Brasília: IPEA.

SILVA, Lindomar Jesus Silva, Ariane Angélica MORENO, Gilmar Antonio MENEGHETTI, José Olenilson COSTA PINHEIRO e Tassiana Maylla FONTOURA DA SILVA. 2015. "A importância da organização dos extrativistas: uma abordagem a partir da comparação das redes estabelecidas em dois municípios produtores de castanha-do-brasil no Estado do Amazonas». Trabalho apresentado no XXX Congreso ALAS Costa Rica, 2015.

SILVA, Osíris Araújo da. 2015. "Debate: o desenvolvimento rural integrado do Amazonas». Revista Terceira Margem Amazônia: 240-244.

SOUSA, José Vasconcelos. 2002. Mediação: O que é?. Portugal: Quimera.

SOUZA, Itamar. 1978. "Migrações internas no Brasil». Dissertação de Mestrado, USP.

TEISSERENC, Pierre e Maria José DA SILVA AQUINO TEISSERENC. 2014. «Território de ação local e de desenvolvimento sustentável: efeitos da reivindicação socioambiental». Revista Sociologia \& Antropologia: 97-125.

TEIXEIRA, Carlos Corrêa. 2009. Servidão humana na selva: o aviamento e o barracão nos seringais da Amazônia. Manaus: Editora Valer.

TOMASI, André. 2016. Cadeia de valor da castanha do Brasil no município de Lábrea/AM. Brasília: Instituto Internacional de Educação do Brasil. 


\section{Derechos de autor}

El Boletín de la Asociación Internacional de Derecho Cooperativo es una revista de acceso abierto lo que significa que es de libre acceso en su integridad inmediatamente después de la publicación de cada número. Se permite su lectura, la búsqueda, descarga, distribución y reutilización legal en cualquier tipo de soporte sólo para fines no comerciales y según lo previsto por la ley; sin la previa autorización de la Editorial (Universidad de Deusto) o el autor, siempre que la obra original sea debidamente citada (número, año, páginas y DOI si procede) y cualquier cambio en el original esté claramente indicado.

\section{Copyright}

The International Association of Cooperative Law Journal is an Open Access journal which means that it is free for full and immediate access, reading, search, download, distribution, and lawful reuse in any medium only for non-commercial purposes, without prior permission from the Publisher or the author; provided the original work is properly cited and any changes to the original are clearly indicated. 